\title{
As experiências de consumo na perspectiva da teoria da cultura do consumo: identificando possíveis interlocuções e propondo uma agenda de pesquisa The experiences of consumption in the perspective of the Consumer Culture Theory: identifying possible dialogues and proposing a research agenda
}

\author{
Marcelo de Rezende Pinto ${ }^{1}$ \\ Jose Edson Lara ${ }^{2}$
}

Resumo

O tema norteador deste trabalho refere-se à constatação de que a pesquisa do consumidor precisa incorporar em suas análises elementos de noção experiencial do consumo e a percepção de que pesquisadores brasileiros têm ignorado um conjunto de temas que leve a uma melhor compreensão dos atos de consumo, de seus sujeitos e contextos culturais. Os principais objetivos aqui estão em discutir uma proposta de interlocução entre a literatura da cultura do consumo e as discussões advindas da noção experiencial do consumo, por meio de temas emergentes de pesquisa; propor alternativas metodológicas para o entendimento das experiências de consumo na perspectiva da cultura de consumo. Conclui-se que não somente é possível, mas altamente desejável, estabelecer ricas e profícuas discussões sobre as possibilidades de interlocução entre esses campos, propondo novas epistemologias e metodologias que contribuam para uma perspectiva que abranja o entendimento do consumo em uma abordagem experiencial e como fenômeno cultural.

Palavras-chave: Consumo, Experiências de Consumo, Teoria da Cultura do Consumo.

\section{Abstract}

The question that this essay addresses is the established fact that consumer research needs to incorporate into its analysis elements of the notion of experiential consumption and the perception that Brazilian researchers have ignored a number of subjects that lead to a better understanding of the acts of consumption, their subjects and cultural contexts. Therefore, the main objective here is to discuss a proposal for dialogue between the literature of consumer culture and discussions arising from the notion of experiential consumption by emerging research issues and propose methodological alternatives to the understanding of consumer experiences with a perspective of consumer culture. The conclusion is that it is not only possible, but also highly desirable, to establish rich and fruitful discussions about the possibilities of dialogue between these fields and propose new epistemologies and methodologies that contribute to a perspective that encompasses the understanding of the demand for both experiential and a cultural phenomenon approaches.

Key-words: Consumption, Consumer Experience, Consumer Culture Theory

Artigo submetido em outubro de 2009 e aceito para publicação em março de 2010.

1 Doutor em Administração pelo CEPEAD/UFMG ; Instituição: Pontifícia Universidade Católica de Minas Gerais - PUC Minas. Endereço : Av. Afonso Vaz de Melo, 1200 - Belo Horizonte - MG, CEP 30640-070. Email: marcrez@hotmail.com

2 PhD, pela Universitat Autònoma de Barcelona, Faculdades Pedro Leopoldo - UNIPEL Endereço : Rua Rodrigues Caldas, 475 / 402 CEP $30190-120$. Email: jedson2010@hotmail.com 


\section{Introdução}

Desde meados da década de 1980, percebeu-se na literatura internacional relacionada à pesquisa do consumidor uma busca por uma extensão da abordagem predominante, na qual o consumidor é simplesmente um tomador de decisão racional (ADDIS; HOLBROOK, 2001). Uma das perspectivas que vão além desta visão refere-se à noção experiencial do consumo. Até então negligenciada pelos pesquisadores, pode ser caracterizada por um fluxo de fantasias (sonhos, imaginação, desejos inconscientes), sentimentos (emoções tais como amor, ódio, raiva, inveja, divertimento) e diversão (prazer hedônico derivado de atividades divertidas, alegres e prazerosas) associado ao consumo (HOLBROOK; HIRSCHMAN, 1982). Assim, é possível incorporar uma série de variáveis que até então não ocupava um lugar de destaque na pesquisa do consumidor: o papel dos sentimentos e das emoções no comportamento de compra, o significado do simbolismo no consumo, a necessidade do consumidor de buscar divertimento e prazer, o papel do consumo para além do ato da compra. E, ainda, levar em conta que os consumidores utilizam bens e serviços para dizer alguma coisa sobre si mesmos, reafirmar suas identidades, definir sua posição no espaço social, declarar seu pertencimento a um ou outro grupo, falar de gênero e etnia, celebrar ou superar passagens, afirmar ou negar sua relações com os outros ou atribuir quaisquer outros significados (ADDIS; HOLBROOK, 2001; DOUGLAS; ISHERWOOD, 2006; SLATER, 2002; McCRACKEN, 2003).

No Brasil, ainda que todo esse movimento por novas perspectivas para a pesquisa do consumidor seja bem mais recente, pode-se também perceber nos últimos anos a tentativa de alguns autores da área de marketing no sentido de 'arejar' o campo com novas abordagens, metodologias e propostas de pesquisa (CASOTTI, 2004, ROSSI; HOR-MEYLL, 2001; CERCHIARO, SAUERBRONN; AYROSA, 2004; FARIA, 2004; MELLO, 2006; ROCHA; ROCHA, 2007; LOURENÇO et al, 2007; PINTO e SANTOS, 2008). Essa perceptível abertura serviu para explicitar e (re)afirmar que a arena dos estudos de consumo, dominada quase que exclusivamente por concepções tradicionais, passou a ser 'invadida' por perspectivas alternativas que ganham, tímida e paulatinamente, notoriedade e espaço nos fóruns de marketing. Contudo, na perspectiva da noção experiencial do consumo, permanecem algumas lacunas e desafios no tocante à definição e delimitação do conceito e, principalmente, uma dificuldade em estabelecer adequadamente os elementos, dimensões ou variáveis associadas à compreensão da experiência de consumo (BRASIL, 2007).

Paralelamente a essa questão, pouco se pesquisou sobre aspectos culturais, simbólicos e ideológicos do consumo no Brasil. Ou seja, tem sido ignorado pelos pesquisadores brasileiros um conjunto de temas que possibilitem uma melhor compreensão dos atos de consumo, de seus sujeitos e contextos, como análises históricas baseadas em fontes primárias; pesquisas de campo e etnografias sobre práticas, padrões e rituais de consumo e compra de diferentes grupos sociais, faixas etárias, gêneros, religiões; mecanismos de mediação aos quais se encontra submetida a cultura material e seu papel no mundo contemporâneo; o estudo dos objetos e o que eles ensinam sobre a sociedade brasileira; entre outros (BARBOSA, 2006).

As indagações neste artigo inserem-se nesse contexto de abertura provocado pelo 'arejamento' do campo por meio de outras perspectivas, como a noção experiencial, e que obriga os pesquisadores a estabelecerem suas conversações com disciplinas das Ciências Humanas e Sociais, como a Filosofia, a Sociologia e a Antropologia, acrescentando-se a visão de que é necessário incorporar nos estudos de consumo questões referentes a aspectos socioculturais, experienciais, simbólicos e ideológicos. Indagações que podem ser resumidas da seguinte forma: é possível estabelecer interlocuções entre a literatura atinente a experiências de consumo e cultura do consumo? Quando afirmamos que o consumo é uma experiência e que qualquer ato de 
consumo é essencialmente cultural, como aspectos simbólicos podem influenciar as experiências de consumo e vice-versa? Como pesquisar essas conexões nas situações cotidianas de consumo? O que poderia ser proposto como questões emergentes para investigação? Quais seriam os métodos e técnicas de pesquisas mais apropriados? Qual a utilidade dessa discussão para o campo da pesquisa do consumidor?

Diante dessas inquietações e da complexidade por elas descortinada, surgiu o interesse de elaborar um trabalho com os seguintes objetivos. Em primeiro lugar, discutir uma proposta de interlocução entre a literatura da cultura do consumo e das discussões advindas da linha de pesquisa que investiga as experiências de consumo, propondo reflexões e questões emergentes para investigação em diferentes áreas da pesquisa do consumidor. Em segundo lugar, propor alternativas metodológicas para o entendimento das experiências de consumo na perspectiva da cultura de consumo. Por fim, trazer à baila algumas questões que possam servir de base para uma ampla discussão, ainda incipiente no Brasil, no sentido de propor novas alternativas para uma pesquisa do consumidor que possa ir além das análises baseadas na teoria microeconômica, na psicologia cognitiva, em métodos analíticos quantitativos, e que esteja mais próxima do universo cultural brasileiro.

A elaboração do artigo se justifica por alguns motivos. Inicialmente, é sempre salutar lembrar que a construção de perspectivas de estudos que comportam campos diferentes do saber costuma representar bons avanços para todas as áreas envolvidas. Nesse caso, pelo caráter interdisciplinar de pesquisas que tentam articular consumo e cultura, é válido afirmar que investigações nesse sentido podem ser relevantes para as disciplinas das ciências sociais, políticas públicas e para a área gerencial. Assim, a originalidade na proposta do artigo está em entender o consumo, conforme já discutido anteriormente, como algo além do processo de decisão de compra - o que é recente nos estudos de pesquisadores brasileiros. E nunca é demais frisar que o artigo pode contribuir para colocar questões, provocar reflexões e suscitar importantes discussões em torno dos questionamentos levantados.

Para isso, estruturou-se o trabalho da seguinte forma: inicialmente, foi elaborada uma seção visando a revisar alguns pontos importantes da literatura, ainda lacunar, sobre experiência de consumo. A seção posterior privilegiará uma discussão sucinta sobre o consumo visto de uma perspectiva antropológica que embasará a próxima discussão acerca da cultura de consumo. As duas próximas seções buscarão apresentar e discutir as contribuições e possibilidades de pesquisa envolvendo questões relativas à experiência de consumo à luz da cultura do consumo, propondo métodos e técnicas para esse fim. Na última seção, algumas reflexões gerais serão apresentadas.

\section{Experiência de Consumo}

A noção de experiência entrou no campo do consumo com o artigo seminal de Holbrook e Hirschman (1982). Esses autores já destacavam a crescente importância, até então negligenciada pelos pesquisadores de consumo, da 'visão experiencial', marcada por um fluxo, associado ao consumo, de fantasias (sonhos, imaginação, desejos inconscientes), sentimentos (emoções tais como amor, ódio, raiva, inveja, divertimento) e diversão (prazer hedônico derivado de atividades divertidas, alegres e prazerosas). Ainda que o artigo desses pesquisadores seja considerado um marco no campo da pesquisa do consumidor, é possível encontrar algumas indícios sobre questões envolvendo a perspectiva experiencial do consumo em trabalhos de autores como Wroe Alderson. que, em 1957, enfatizava a importância da experiência no consumo em seu trabalho "Marketing Behavior and Executive Action" ou no livro Quality and Competition, do economista Lawrence Abbott, também da década de 1950. Além do mais, um recente trabalho conduzido por Stanley Lebergott, em 1993, 
intitulado "Pursuing Happiness", traça o conceito de experiência de consumo por meio de contribuições de John Maynard Keynes, Alfred Marshall e até mesmo Adam Smith (HOLBROOK, 2006a).

Apesar disso e passados quase trinta anos da publicação do trabalho de Holbrook e Hirschman (1982), o conceito ainda parece ser elemento chave na pesquisa do consumidor (CARÙ; COVA, 2003), embora seja fácil perceber que algumas lacunas e desafios permaneçam evidentes (BRASIL, 2007). Isso se constata na existência de diferentes definições para o conceito e, principalmente, em uma dificuldade em estabelecer adequadamente os elementos, dimensões ou variáveis associadas à compreensão da experiência de consumo (BRASIL, 2007). Para Holbrook (2006b), essas dificuldades advêm da insistência de muitos autores do campo do comportamento do consumidor em adotar a perspectiva do processamento de informação aliada à visão de que o consumidor é uma 'máquina' racional que objetiva sempre a maximização de aspectos utilitários e com capacidade cognitiva limitada (atenção seletiva, percepção distorcida, memória restrita, entre outros).

Com relação à dificuldade de se estabelecer uma conceituação para o termo 'experiência de consumo', Carù e Cova (2003) tentaram propor uma contribuição no sentido de estabelecer a definição da palavra experiência em diferentes áreas do conhecimento. O Quadro 1 apresenta essas definições.

Quadro 1-Definições de experiência

\begin{tabular}{|l|l|}
\hline Área do conhecimento & Definição \\
\hline Ciência & $\begin{array}{l}\text { No sentido genérico herdado das ciências positivas, uma experiência é similar a um } \\
\text { experimento baseado em fatos e dados objetivos que podem ser generalizados. É } \\
\text { importante reconhecer uma distinção entre experiência em geral e uma experiência } \\
\text { científica. Uma experiência comum fornece ao indivíduo um conhecimento particular, } \\
\text { enquanto uma experiência científica oferece um conhecimento universal válido para todos. }\end{array}$ \\
\hline Filosofia & $\begin{array}{l}\text { Uma experiência é um "teste" pessoal que geralmente transforma o indivíduo. A } \\
\text { experiência é importante quando o que acontece é traduzido em conhecimento, não } \\
\text { somente quando permanece como uma simples ocorrência vivida. }\end{array}$ \\
\hline Sociologia e Psicologia & $\begin{array}{l}\text { Uma experiência é uma atividade subjetiva e cognitiva que permite a um indivíduo se } \\
\text { desenvolver. A noção de experiência é geralmente definida como uma 'atividade } \\
\text { cognitiva', 'um teste', um meio de construir a realidade e, acima de tudo, verificá-la. }\end{array}$ \\
\hline Antropologia e Etnologia & $\begin{array}{l}\text { Experiência é a forma como indivíduos vivem sua cultura e, mais precisamente, como } \\
\text { eventos são recebidos pela consciência. A experiência se distingue do conceito de evento, } \\
\text { considerado como alguma coisa geral que acontece com os outros, com a sociedade, com } \\
\text { o mundo. A experiência é qualquer coisa de singular que acontece com o indivíduo. } \\
\text { Também se diferencia do mero comportamento individual, que pode ser descrito por um } \\
\text { observador externo e diz respeito à rotina vivenciada pelo consumidor. }\end{array}$ \\
\hline
\end{tabular}

Fonte: Elaborado com base em Carù e Cova (2003).

Já no campo das ciências gerenciais, esses autores concluíram que definições não são unitárias. Para Holbrook e Hirschman (1982), uma experiência é uma ocorrência pessoal, não raramente com significante importância emocional, fundada na interação com estímulos de produtos e serviços consumidos. Na visão desses autores, vale ressaltar que a abordagem experiencial é fenomenológica e considera o consumo como um estado primariamente subjetivo de consciência com uma variedade de significados simbólicos, respostas hedônicas e critérios estéticos. Pullman e Gross (2003) estabelecem que experiências são inerentemente emocionais e pessoais e abrangem fatores como interpretações pessoais de uma situação com base em um histórico cultural, experiências anteriores, humor e traços de personalidade. 
Em uma visão mais operacional da abordagem experiencial, Schmitt (2000) define experiências como acontecimentos individuais que ocorrem como resposta a algum estímulo, não sendo espontâneas, mas induzidas. $\mathrm{O}$ autor também ressalta que as experiências são resultado do encontro e da vivência de situações, sendo estímulos criados para os sentidos, para os sentimentos e para a mente. Pine II e Gilmore (1998), no mesmo sentido, propõem que uma experiência ocorre quando uma companhia intencionalmente usa produtos e serviços para engajar consumidores em uma atividade que cria um evento memorável. Na visão desses autores, dessa forma, as experiências são inerentemente pessoais, existindo somente na mente das pessoas que dela participam. Assim, dificilmente duas pessoas terão a mesma experiência, porque cada experiência deriva de interação estabelecida entre o evento e o estado mental do indivíduo.

Também é importante ressaltar que, na perspectiva experiencial, a experiência de consumo não deve ser reduzida às atividades de compra, isto é, à experiência no ponto de venda (FALK; CAMPBELL, 1997), muito menos às atividades pós-compra, ela inclui uma série de outras atividades que podem ser divididas em quatro grandes estágios. O Quadro 2 a seguir descreve esses estágios.

Quadro 2 - Estágios das experiências de consumo

\begin{tabular}{|l|l|}
\hline Estágio da experiência de consumo & Descrição \\
\hline Experiência pré-consumo & $\begin{array}{l}\text { Envolve a busca por algo, planejamento, sonhos, prever ou } \\
\text { imaginar a experiência. }\end{array}$ \\
\hline Experiência de compra & $\begin{array}{l}\text { Deriva da escolha, pagamento e encontro do serviço e do } \\
\text { ambiente }\end{array}$ \\
\hline Experiência de consumo central & $\begin{array}{l}\text { Inclui a sensação, a saciedade, a satisfação/insatisfação, irritação, } \\
\text { transformação. }\end{array}$ \\
\hline Experiência de consumo lembrada & $\begin{array}{l}\text { Envolve o ato de olhar fotos para reativar na memória a } \\
\text { experiência vivida, que é baseada nas histórias descritas e nos } \\
\text { argumentos divididos com os amigos, e que recebe uma } \\
\text { classificação na memória. }\end{array}$ \\
\hline
\end{tabular}

Fonte: Elaborado com base em Carù e Cova (2003)

Com base nessa classificação, podem-se apresentar dois pontos para argumentação. O primeiro é que essa divisão em quatro estágios da experiência de consumo leva à constatação de que os pesquisadores do consumo adotam uma conceituação de experiência mais próxima daquela usada nas Ciências Sociais e na Filosofia. O segundo é que boa parte dos estudos de consumo no campo de marketing tem sido reduzidos à tomada de decisão e processos derivados desse processo. Contudo, parece plausível acreditar que essa é apenas uma das partes que compõem o consumo. Isso leva à constatação de que sentimentos diversos como prazer, emoção, alegria, raiva, frustração, reconhecimento, tédio, entre diversos outros, não derivam exclusivamente do ato de compra, mas do fato de que comprar pode ser uma forma de socialização. $\mathrm{Ou}$, como enfatiza Carù e Cova (2003), a experiência é definida como um episódio subjetivo na construção e transformação do indivíduo, porém, com ênfase nas emoções e nos sentidos vividos durante a imersão.

É interessante notar que a noção de experiência se encaixa na discussão de uma cultura pós-moderna. Featherstone (1995) destaca que, nos shoppings, nas galerias e nas grandes lojas de departamentos. a compra é 
raramente uma transação econômica racional e calculista de maximização de utilidade. Ao contrário, nas cidades pós-modernas, constata-se que a compra precisa transformar-se numa experiência na qual as pessoas tornam-se atores que se movimentam em meio a imagens espetaculares, projetadas para produzir suntuosidade e luxo, ou até mesmo evocar conotações de lugares exóticos, e uma nostalgia das harmonias emocionais do passado.

No que concerne à busca por estabelecer elementos, dimensões e variáveis, a literatura é ainda mais lacunar. Alguns modelos vêm sendo propostos, entre eles, o servicescape, por Bitner (1992), embora não tenha sido concebido dentro de uma perspectiva experiencial. Para Bitner (1992), as respostas ou reações podem ser divididas em três grupos: cognitivas, emocionais e físicas. O estudo de Pullman e Gross (2003) foca a criação de experiências considerando contextos. Segundo esses autores, experiências podem ser definidas dentro de um contexto físico, um contexto relacional e um determinado período de tempo. Em estudo exploratório conduzido por Lofman (1991), o autor propõe que os principais elementos relacionados ao consumo experiencial incluem o contexto ou situação na qual a experiência acontece, vários fatores atinentes ao consumo em si (pensamentos, sentimentos, atividades, avaliação) e a estimulação dos consumidores por meio de modalidades sensoriais tais como aroma, iluminação, sonorização, entre outros. Já Goulding (2000), ao pesquisar experiências de visitantes de museus, conclui que a qualidade da experiência é derivada de quatro grandes grupos de fatores: sociocultural, cognitivo, de orientação psicológica e físico/ambiental. No Brasil, Azevedo Barbosa (2006) propõe um esquema referencial para a compreensão do processo de oferta e consumo de experiências extraordinárias em serviços. De acordo com esse esquema, uma experiência extraordinária em serviços é função dos elementos da oferta de serviços (experiências sensoriais, afetivas, físicas e relacionais) somada ao processo de consumo ou à experiência de consumo em si. É importante lembrar que o processo de consumo sofre influência das dimensões das experiências extraordinárias (motivação, expectativa, interação, envolvimento, satisfação e encantamento).

Além dessa discussão, destaca-se aí, entretanto, uma lacuna na noção de experiência de consumo, na qual não se discute a dimensão simbólica dessas experiências, construída na interação social entre os indivíduos. Isto é, os consumidores contemporâneos definem as experiências de consumo como representantes de algo mais do que situações aparentemente comuns. Nesse sentido, expressando valores por meio do consumo, é possível verificar a "celebração" de sua ligação com a sociedade como um todo. Toma vulto, portanto, nesse contexto, entender o consumo numa perspectiva antropológica.

\section{O consumo numa visão antropológica}

Em estudos desse campo, parte-se de uma crítica às interpretações apoiadas em teorias econômicas (principalmente as de base neoclássica funcionalista) que reduzem o fenômeno do consumo à esfera individual, no qual as pessoas são vistas como seres puramente racionais, que realizam suas compras por meio de uma escolha vinculada à busca da maximização de sua utilidade. Essa lógica calculista originada do modelo economicista não permitia a possibilidade de discussão da dimensão simbólica e social do consumo (BARROS, 2006). A premissa fundamental do consumo numa visão antropológica é a de que, na esfera do consumo, homens e objetos adquirem sentido, produzem significações e distinções sociais (ROCHA, 1995). Em suma, são os objetos que trazem a presença e/ou ausência de identidades, visões de mundo ou estilos de vida. Tanto roupas, automóveis quanto bebidas, cigarros comidas, habitações e enfeites dos mais diversos não são consumidos de forma neutra, pelo contrário, são antropomorfizados para levarem aos seus consumidores 
individualidades e universos simbólicos que a eles foram atribuídos (ROCHA, 1995; DOUGLAS; ISHERWOOD, 2006).

Uma das primeiras teorias do consumo com enfoque na abordagem simbólica surgiu no início do século XX, no livro A teoria da classe ociosa, de Thostein Veblen. Nessa obra, Veblen sustenta a tese de que há uma modalidade de consumo que é ostentatória, e cuja finalidade é demonstrar a condição social. $\mathrm{O}$ autor chama esse consumo de conspícuo, manifestado socialmente pela classe ociosa. O aparecimento de uma classe ociosa coincide com o início da propriedade, uma vez que as duas instituições resultam do mesmo conjunto de forças econômicas (VEBLEN, 1988).

A 'novidade' apresentada por Veblen em sua obra reside no fato de que ele muda o foco na forma de compreender o objetivo da aquisição e da acumulação de bens ampliando-o para além do objetivo economicamente legítimo da aquisição que caberia à teoria econômica explicar. Ele concebe o consumo como um atendimento tanto das necessidades físicas do consumidor como de suas necessidades mais elevadas, espirituais, estéticas ou intelectuais. Em outras palavras, essa última classe de necessidades seria atendida indiretamente pelo consumo de bens.

Marshall Sahlins, no livro Cultura e Razão Prática, segue a mesma linha de Veblen ao defender uma crítica antropológica da ideia de que as culturas humanas são formuladas com base na atividade prática e no interesse utilitário. Para ele, o significado dos bens é a propriedade específica do objeto antropológico. As culturas são ordens de significado de pessoas e coisas. Sahlins (2003) afirma que o funcionalismo utilitário é uma cegueira funcional, visto que o conteúdo é apreciado somente por seu efeito instrumental, sendo sua consistência interna, por consequência, modificada por sua utilidade externa. Porém, nenhuma explicação funcional, por si só, é suficiente, já que o valor funcional é sempre relativo a um esquema cultural. Dessa forma, as finalidades assim como as modalidades de produção vêm do lado cultural. Por sua vez, as forças materiais por si só não têm vida. Seus movimentos específicos e consequências determinadas somente podem ser estipulados agregando-os às coordenadas da vida cultural.

Dessa visão cultural deriva simbolicamente todas as utilidades. Na medida em que 'utilidade' é o conceito de 'necessidade' apropriado a uma ordem cultural, ele deve incluir uma representação por meio das propriedades concretas do objeto, assim como das relações entre pessoas. Isto é, "o 'sistema de necessidades' deve ser sempre relativo, não avaliável como tal pela necessidade e, em conseqüência, simbólico por definição" (SAHLINS, 2003, p. 151). No caso dos bens, para esse autor, eles ficam como um código-objeto para a significação e avaliação de pessoas e ocasiões, funções e situações. Assim, operando em uma lógica específica de correspondência entre contrastes materiais e sociais, a produção é, portanto, a reprodução da cultura em um sistema de objetos.

Outro autor que discute antropologicamente o consumo é Jean Baudrillard, optando por seguir uma linha do consumo como um elemento de discriminação e diferenciação social. Para Baudrillard (2005), o consumo é uma atividade sistemática de manipulação de significados, com uma ênfase maior na expressividade e não em seus aspectos funcionais, isto é, a mercadoria é o próprio significado. Nesse sentido, a circulação, a compra, a venda, a apropriação de bens e de objetos/signos diferenciados constituem hodiernamente a nossa linguagem e o nosso código, por cujo intermédio toda a sociedade se comunica. Seria, dessa forma, a estrutura de consumo a sua língua em relação à qual as necessidades e os prazeres individuais não passam de efeitos de palavra (BAUDRILLARD, 2005). 
A obra da antropóloga Mary Douglas e do economista Baron Isherwood, publicada pela primeira vez, em 1978, com o título de "The world of goods: towards an anthropology of consumption", é considerada um clássico da Antropologia do Consumo. Nessa obra, os autores defendem a ideia de que o consumo é algo ativo e constante em nossa vida diária e nela desempenha um papel central como estruturador de valores que constroem identidades, regulam relações sociais, definem mapas culturais. Nesse sentido, os bens são investidos de valores criados socialmente para expressar tanto categorias e princípios, quanto para cultivar ideias, fixar e sustentar estilos de vida ou enfrentar mudanças. Douglas e Isherwood (2006) criticam a perspectiva racional dos modelos de pesquisa do consumidor, pois a ideia do indivíduo racional é uma abstração impossível da vida social. Na visão deles, seria absurdo agregar milhões de indivíduos que compram e usam diversos produtos e serviços sem considerar as transformações que eles mesmos provocam ao compartilharem o consumo. Ademais, "os bens são neutros, seus usos são sociais; podem ser usados como cercas ou pontes" (DOUGLAS; ISHERWOOD, 2006, p. 36). Como o valor é conferido pelos juízos humanos, o valor de cada bem depende de seu lugar numa série de outros objetos complementares. Em vez de tomar um objeto por vez, a abordagem antropológica captura todo o espaço de significação em que os objetos são usados depois de comprados. "Toma a realidade como dada e acredita que ela é socialmente construída" (p. 41).

Para Douglas e Isherwood (2006), haveria três grandes conjuntos de bens: os de consumo geral (primários), os tecnológicos (secundários) e os informacionais (terciários). Os bens primários se limitariam a camadas mais pobres da população, pois, para atingir o topo, ou seja, os bens terciários, é preciso não somente um nível de renda mais elevado, mas também uma maior competência para julgar e escolher. Neste sentido, vale destacar o foco na distinção: o consumo tem o poder classificatório de comunicar a diferença e se transforma em um meio de comunicação e relacionamento.

Esses autores ressaltam que as posses materiais ao mesmo tempo em que fornecem comida e abrigo também têm outro importante uso: estabelecem e mantêm relações sociais. Dessa forma, em vez de supor que os bens sejam primeiramente necessários à subsistência e à exibição competitiva, eles são necessários também para dar visibilidade e estabilidade às categorias da cultura, sendo prática da investigação etnográfica supor que todas as posses materiais carregam significação social e concentram parte principal da análise cultural em seu uso como comunicadores.

Daniel Miller, outro antropólogo e importante estudioso do tema do consumo, também pode ser citado como uma referência importante. Miller (2002) resgata um tema abandonado pelos antropólogos no século XIX - a cultura material. No âmbito dessa subdisciplina, ele salienta que o ato de comprar deve ser visto como um meio de o pesquisador descobrir, mediante a observação cuidadosa das práticas das pessoas, algo sobre seu relacionamento. $\mathrm{O}$ ato de comprar é a interpretação do outro como o sujeito que deseja. O objetivo de comprar, portanto, não é tanto comprar o que as pessoas desejam, mas lutar para continuar se relacionando com os sujeitos que desejam essas coisas.

Outro autor que contribui para as discussões da Antropologia do Consumo é Colin Campbell. As contribuições desse autor advêm de vários pontos. Em primeiro lugar, Campbell (2001) advoga em defesa de que paralelamente à Revolução Industrial houve uma Revolução do Consumo que é negligenciada pelos pesquisadores. Ou seja, ele compreende que a Revolução Industrial constituiu uma dramática transformação, pois houve um concomitante desenvolvimento e ampliação do consumo. Contudo, essa nova propensão ao consumo teve origem numa mudança de valores e atitudes, uma mudança que não se restringiu ao significado econômico do comportamento do consumidor. Essas mudanças que constituiriam uma revolução do consumo 
foram provenientes da expansão das atividades das horas vagas. Surgiram novas atividades como a leitura de romances e houve a ascensão da moda e do amor romântico.

Além disso, Campbell (2001) percebe o consumo moderno como uma consequência do padrão de gratificação das pessoas. Dessa forma, o consumo é alimentado por sentimentos românticos existentes nas associações de imaginário por parte dos consumidores. Ele também defende a ideia do comportamento de compra hedonista. A chave para o desenvolvimento do hedonismo moderno está no deslocamento das sensações para as emoções, uma vez que é destas que a estimulação poderosa e prolongada pode ser combinada com qualquer grau significativo de controle autônomo. Por fim, esse mesmo autor afirma que o espírito do consumismo moderno é tudo, menos materialista, isto é, sua motivação básica é o desejo de experimentar na realidade os dramas agradáveis que já foram desfrutados na imaginação. Assim, cada 'novo' produto é visto como uma nova possibilidade de concretizar essa ambição.

Em suma, conforme enfatizado por Barbosa e Campbell (2006), a proposta dos estudos relacionados à Antropologia do Consumo é explorar as relações entre cultura, consumo e as diversas concepções tangíveis às pessoas, indivíduos, relações sociais, formas de mediação e negociação a que o fenômeno do consumo parece estar ligado no mundo contemporâneo.

A partir dessa discussão que procurou focar na visão antropológica do consumo, tendo em vista autores reconhecidos na literatura da área, torna-se importante tecer algumas considerações acerca do campo de pesquisa denominado "cultura do consumo".

\section{Teoria da Cultura do Consumo}

Os últimos vinte anos da pesquisa do consumidor têm produzido um fluxo de pesquisas voltadas para a análise de aspectos socioculturais, experienciais, simbólicos e ideológicos do consumo. Cunhada por autores como "Teoria da Cultura do Consumo" (ARNOULD; THOMPSON, 2005; McCRACKEN, 2003), muitas das discussões advindas dessa linha de pesquisa vêm sendo publicadas em periódicos internacionais importantes tais como European Journal of Marketing; Consumption, Markets and Culture; International Journal of Research in Marketing; Journal of Consumer Culture; e Journal of Marketing, entre outros. Segundo Arnould e Thompson (2005), a teoria da cultura do consumo não é unificada, pois se refere a uma família de perspectivas teóricas que direcionam às relações dinâmicas entre ações de consumo, o mercado e significados culturais. Mais do que ver a cultura como um sistema homogêneo de significados compartilhados coletivamente, a teoria da cultura do consumo explora a distribuição heterogênea dos significados e a multiplicidade de grupos e manifestações culturais que existem nas diversas formações sócio-históricas atuais, ou seja, a linha de pesquisa também conceitualiza um sistema interconectado de imagens, textos e objetos produzidos comercialmente que grupos utilizam por meio da construção de práticas, identidades e significados sobrepostos para a criação de sentidos em seus ambientes e para orientar as experiências e vidas de seus membros (ARNOULD; THOMPSON, 2005).

Slater (2002) enfatiza que o tema central da teoria da cultura do consumo é o modo pelo qual ela articula as questões no tocante a como devemos ou queremos viver, à forma de organização da sociedade. Isso tudo é feito no plano da vida cotidiana: a estrutura material e simbólica dos lugares onde vivemos e nosso modo de viver nesses lugares; o que comemos; as roupas que usamos; os tipos de escassez e de desigualdades que sofremos e assim por diante. 
Dessa forma, pode-se constatar que cultura e consumo encontraram uma forte ligação, pois o consumo é moldado em todos os seus sentidos por considerações culturais. Os consumidores usam o significado dos bens de consumo para expressar categorias e princípios culturais, cultivar ideias, criar e manter estilos de vida, (re)construir noções de si e sobreviver a mudanças sociais (McCRACKEN, 2003). O consumo deve ser visto não como consumo de valores de uso, de utilidades materiais, mas como o consumo de signos (BAUDRILLARD, 2005; FEATHERSTONE, 1995).

Nesse ponto, é importante enfatizar a visão de Belk (1988). Esse autor defende a idéia de que os consumidores consideram seus pertences como parte deles. Ele também propõe que os objetos constituem uma extensão do self de cada pessoa. Assim, é necessário destacar a dimensão social e coletiva dos produtos e das atividades de consumo, podendo-se estabelecer a ligação entre os significados assumidos na relação do indivíduo com os objetos e a inserção desses objetos em diferentes grupos sociais.

Nesse sentido, cumpre salientar alguns pontos que parecem não poder passar despercebidos pelos pesquisadores do campo. Em primeiro lugar, as teorias da cultura do consumo podem ser entendidas como uma construção de experiências, significados e ações, ou seja, a cultura do consumo não determina a ação como força causal, mas sim como um imbricado sistema de valores, sentimentos e pensamentos que são construídos e negociados na interpretação da vida social (THOMPSON; HIRSCHMAN, 1995). Em segundo lugar, a perspectiva da teoria da cultura do consumo tem sido desenvolvida tanto por meio de estudos empíricos, que analisam como manifestações particulares de cultura do consumo são constituídas, mantidas, transformadas e formatadas pelas forças históricas mais amplas (tais como narrativas culturais, mitos e ideologias), quanto embasada em circunstâncias socioeconômicas específicas e sistemas de mercado particulares (ARNOULD e THOMPSON, 2005). Outra questão, mais relacionada à metodologia, remete ao fato de que as teorias da cultura do consumo focalizam as dimensões experienciais e socioculturais do consumo que não são plenamente acessíveis por meio de experimentos, surveys ou modelagem de banco de dados.

Assim, a leitura do comportamento de consumo deve se dar por meio de uma busca de significados que são criados e transferidos, uma vez que os bens de consumo têm uma significância que vai além do caráter utilitário e do valor comercial (McCRACKEN, 2007). Para esse autor, uma das grandes limitações das atuais abordagens ao estudo do significado cultural dos bens de consumo é a dificuldade de se perceber que esse significado está em constante trânsito. Dessa forma, de modo geral, o significado cultural é absorvido do mundo culturalmente constituído para um bem de consumo. Em seguida, o significado é absorvido do objeto e transferido para um consumidor individual. Isso quer dizer que "o significado cultural se localiza em três lugares: no mundo culturalmente constituído, no bem de consumo e no consumidor individual” (McCRACKEN, 2007, p. 100).

Em suma, a teoria da cultura do consumo é organizada com base em uma série de questões teóricas atinentes ao relacionamento entre a identidade individual e coletiva dos consumidores: a cultura criada e corporificada no mundo vivido dos consumidores; processos e estruturas das experiências vivenciadas; e a natureza e o dinamismo das categorias sociológicas por meio das quais essa dinâmica da cultura do consumo é influenciada (ARNOULD e THOMPSON, 2005). 


\section{Possíveis interlocuções e proposição de uma agenda de pesquisas}

De início, é importante salientar que parece haver uma interlocução entre o campo da experiência de consumo e da teoria da cultura do consumo que não tem sido contemplada pelos pesquisadores do consumidor. Em primeiro lugar, a discussão que ganha relevo certamente remete ao papel do simbolismo envolvido nas experiências de consumo. Esta faceta do consumo é estudada por alguns pesquisadores interessados principalmente no consumo não somente de produtos, mas também de experiências, como um canal para o consumidor comunicar seus valores por meio dos significados dessas experiências. A questão do simbolismo tem sido direcionada para outros conceitos adicionais; o significado simbólico, por exemplo, serve como fonte de valores pessoais. Nessa perspectiva, os significados atribuídos às diversas experiências do cotidiano resultam de uma construção social (ADDIS; HOLBROOK, 2001). A interpretação do consumo como uma experiência holística é uma face adicional da visão experiencial que deve ser levada em conta. Quando aplicada mais generalizadamente, a perspectiva holística sugere que as inúmeras atividades relacionadas ao consumo não são separadas e isoladas do resto do mundo do consumidor. Isto é, todas essas atividades estão fortemente relacionadas aos sentimentos da pessoa, às suas relações com outras pessoas, à sociedade como um todo e à vida total do consumidor. Existe uma construção 'socialmente articulada' que interfere na forma como os consumidores percebem suas experiências de consumo.

Em segundo lugar, as experiências de consumo levam em consideração questões eminentemente simbólicas e permeadas por sensações diversas como sonho, imaginação, alegria, prazer, status e assim por diante. É justamente nesse ponto que se apoia todo o referencial da teoria da cultura do consumo, pois as práticas de consumo e posse, particularmente as dimensões hedônicas, estéticas e ritualísticas, têm sido as 'constelações mais amplamente estudadas - de fenômenos identificados com a cultura do consumo. Ratificando essa questão, conforme salientado por Carù e Cova (2003), as relações com o mercado são somente uma das formas de relacionamento do consumidor. As relações sociais, todavia, estão mais presentes na sua vida cotidiana e, portanto, podem ser consideradas como muito mais decisivas em suas experiências. Assim, segundo a sociologia do consumo, as relações sociais moldam as experiências de consumo.

Em terceiro lugar, partindo-se do pressuposto de que a base do marketing é a troca, e que esta muitas vezes é simbólica, ou seja, é construída no nível da ação social e é impregnada de significado de elaboração coletiva da sociedade de consumo, pode-se perceber também que muitas dessas trocas são construídas não numa abordagem tradicional, mas sim numa perspectiva experiencial, na qual o consumidor participa ativamente do processo quase sempre marcado por sensações diversas. Ademais, vale frisar que estas duas abordagens parecem contribuir para aumentar o conhecimento até então existente acerca dos processos culturais que participam das construções de experiências no mercado, além de aumentar nosso entendimento das estratégias dos consumidores no tocante a produção, mediação e consumo de experiências. Em suma, a interlocução que parece existir entre os dois campos caminha no sentido de que, nos aspectos experienciais do consumo, uma dimensão social não pode ser negligenciada, ressaltando o seu significado simbólico-cultural. Tal significado não se limita ao consumidor individual, isolado, obediente e sempre fiel à simples ordem econômica, material e funcional do consumo, mas está sempre em trânsito, sendo criado e transferido, desfilando fugaz no mundo culturalmente constituído, nos produtos e serviços, e nos próprios consumidores. Essa possibilidade de diálogo talvez seja a grande contribuição deste ensaio para a pesquisa do consumidor.

Sendo assim, é possível vislumbrar uma riqueza de temáticas de pesquisas que podem ter como base a interlocução aqui apresentada. Temáticas que tenham como preocupação não somente questões simbólicas do cotidiano dos consumidores em diferentes situações ou experiências de consumo, mas também discussões 
relacionadas às idiossincrasias de consumidores das mais diversas classes sociais, regiões, faixas etárias, grupos sociais e "tribos". Conforme já explanado anteriormente, no campo das experiências de consumo é fácil perceber que algumas lacunas e desafios ainda permanecem evidentes, principalmente no que tange à abrangência do conceito de experiência de consumo bem como no estabelecimento adequado dos elementos, dimensões ou variáveis associadas a ele. Por outro lado, no que se refere aos estudos relacionados à cultura do consumo, Arnould e Thompson (2005) estabelecem as seguintes fronteiras a serem transpostas ao se propor uma agenda de pesquisas: (1) identidade do consumidor; (2) culturas de mercado; (3) 'modelos' sóciohistóricos de consumo e (4) ideologias de mercado e estratégias interpretativas dos consumidores.

Não é escusado salientar que as temáticas de pesquisa compõem um campo de investigação complexo, uma vez que englobam várias atividades, atores e um conjunto de 'bens' não necessariamente restritos à forma de mercadorias. Estudos desse tipo vão contemplar o caráter eminentemente 'intangível' do consumo na perspectiva experiencial e frente à subjetividade do simbolismo verificado nas diversas situações do cotidiano.

Com base nas discussões propostas por Arnould e Thompson (2005), e para além delas, elaborou-se o quadro 3 com uma 'agenda' composta por possíveis questões de pesquisa que parecem emergir frente às lacunas e fronteiras existentes nos campos da experiência e cultura do consumo. Fica implícito, contudo, que a lista de questões emergentes aqui apresentadas não tem a pretensão de ser exaustiva, mas o intuito de salientar algumas possibilidades para investigação.

A análise cuidadosa das questões emergentes para pesquisa descortina a grande tônica do trabalho: para um entendimento mais amplo do consumo não se pode deixar de lado a perspectiva experiencial, nem tampouco aspectos culturais e simbólicos. As investigações a serem conduzidas não podem perder de vista a integração da noção experiencial do consumo e da teoria da cultura do consumo, a qual seria uma tentativa de entender os diversos relacionamentos que surgiriam entre os consumidores, entre empresa e consumidor, e entre as marcas e os consumidores diretamente em um contexto social, tratando a experiência como um empreendimento de construção conjunta.

Consumir, no sentido amplo que este ensaio defende, é algo inerente ao ser humano. E o desejo por ter acesso a bens, serviços e experiências, e usufruir deles, não está somente relacionado à quantidade de recursos disponíveis, nem a aspectos utilitaristas, mas, sim, diretamente influenciado pela interação com o sistema cultural e simbólico envolvido no fluxo da vida social cotidiana. Como bem enfatiza Rocha (2006), para entender o consumo, é preciso conhecer como a cultura constrói a experiência na vida cotidiana, como atuam os códigos culturais que dão coerência às práticas e como, por meio do consumo, classificamos objetos e pessoas, elaboramos semelhanças e diferenças. No mesmo sentido, todo o processo de consumo, incluindo as experiências, serve para moldar comportamentos, preferências, relações sociais, estilos de vida, padrões de consumo além da própria identidade e autoconceito do indivíduo. Assim, ao tentar compreender como se constroem os significados dos serviços e como estes influenciam a experiência de consumo de serviços; como aspectos culturais e simbólicos moldam a relação entre empresas e clientes; como os consumidores articulam aspectos experienciais e simbólicos nos estabelecimentos varejistas; como os códigos culturais influenciam e/ou dificultam a mudança de comportamentos sociais que são eminentemente experienciais, entre outras tantas questões, os pesquisadores não podem perder de vista a interlocução entre experiências de consumo e a teoria da cultura do consumo. 


\section{Quadro 3 - Questões Emergentes para Pesquisa Frente às Lacunas Existentes nos Campos da Experiência de Consumo e Cultura do Consumo}

\begin{tabular}{|c|c|}
\hline Abordagens & Questões Emergentes para pesquisa \\
\hline Serviços & $\begin{array}{l}\text { Situações de prestação de serviços como turismo, diversão, lazer e entretenimento, nas quais fica } \\
\text { evidente a noção experiencial do consumo, podem ser influenciadas pelos códigos culturais } \\
\text { elaborados coletivamente? Em que medida os serviços podem ser utilizados, de forma igual ou } \\
\text { diferentemente dos produtos, para dizer alguma coisa sobre os consumidores, para reafirmar suas } \\
\text { identidades, para definir sua posição no espaço social, para declarar seu pertencimento a um ou outro } \\
\text { grupo, para falar de gênero e etnia, para celebrar ou superar passagens, para afirmar ou negar suas } \\
\text { relações com os outros? }\end{array}$ \\
\hline Relacionamento & $\begin{array}{l}\text { Qual o papel dos relacionamentos na experiência de consumo? Qual o efeito das questões culturais e } \\
\text { sociais no relacionamento entre empresas e consumidores? Todas as sociedades veem o aspecto } \\
\text { relacional da mesma forma? Como os códigos culturais podem influenciar os relacionamentos e isto } \\
\text { interferir nas experiências de consumo? Em que medida o relacionamento influencia o consumo } \\
\text { hedônico? Qual a relação entre a criação da identidade do consumidor e os relacionamentos } \\
\text { consumidor/empresa? }\end{array}$ \\
\hline Varejo & $\begin{array}{l}\text { De que maneira estratégias relacionadas ao ponto de venda, eminentemente experienciais, tais como } \\
\text { odorização, sonorização, experimentação, merchandising, iluminação, etc. podem sofrer influência } \\
\text { da construção social dos significados e vice-versa? Como os significados culturais de datas } \\
\text { comemorativas tão exploradas pelo varejo - Dia das Mães, Dia dos Namorados, Natal, entre outras - } \\
\text { podem influenciar as experiências de consumo? }\end{array}$ \\
\hline Marketing e Sociedade & $\begin{array}{l}\text { Até que ponto, as experiências de "consumo coletivo" entendido mediante o conjunto de serviços } \\
\text { fornecidos pelo Estado sofrem influência dos códigos culturais estabelecidos? Como os códigos } \\
\text { culturais influenciam e/ou dificultam a mudança de comportamentos sociais que são eminentemente } \\
\text { experienciais? Como as campanhas de marketing social podem se apropriar dos sistemas culturais } \\
\text { para construir mensagens mais eficazes? De que modo as campanhas de responsabilidade social são } \\
\text { interpretadas pelos consumidores e como podem influenciar as experiências de consumo dos } \\
\text { produtos social e ambientalmente corretos? }\end{array}$ \\
\hline $\begin{array}{l}\text { Novos produtos e } \\
\text { serviços }\end{array}$ & $\begin{array}{l}\text { Qual é a importância de aspectos simbólicos e experienciais do consumo na criação e } \\
\text { desenvolvimento de produtos e serviços? Como os profissionais podem se apropriar desse } \\
\text { conhecimento? }\end{array}$ \\
\hline Pesquisa de mercado & $\begin{array}{l}\text { De que forma o 'fator cultural' pode ser mais bem investigado nas pesquisas de mercado que } \\
\text { envolvem produtos nos quais a noção experiencial é fundamental? }\end{array}$ \\
\hline Marcas & $\begin{array}{l}\text { De que maneira as conexões afetivas com a marca são construídas por meio das experiências de } \\
\text { consumo? Qual o peso dos códigos culturais na influência da construção de conexões afetivas com } \\
\text { os consumidores numa perspectiva experiencial? }\end{array}$ \\
\hline $\begin{array}{l}\text { Comunicação } \\
\text { marketing }\end{array}$ & $\begin{array}{l}\text { Quais mensagens normativas a mídia veicula sobre consumo? Como os consumidores interpretam as } \\
\text { mensagens veiculadas na mídia e formulam respostas críticas? De que forma os produtos e serviços } \\
\text { adquirem sentido ao serem inseridos nas redes de relações sociais construídas na mídia? Quais } \\
\text { aspectos culturais são utilizados para se comunicar as experiências de consumo? }\end{array}$ \\
\hline Outras & $\begin{array}{l}\text { De que maneira a emergência do consumo como uma prática humana dominante reconfigura o } \\
\text { esquema de interpretação e ação dos consumidores em experiências de consumo? O que é a } \\
\text { sociedade de consumo e como ela é constituída e mantida? Em que medida a sociedade de consumo } \\
\text { interfere na construção de significados das experiências de consumo? Qual é o sentido das } \\
\text { experiências de consumo no contexto cultural atual? }\end{array}$ \\
\hline
\end{tabular}

\section{Fonte: Elaborado pelos autores}

Em suma, todas as propostas elencadas que vão desde a oferta de serviços até as comunicações de marketing, passando pelo relacionamento entre empresas e clientes, varejo e as relações entre marketing e sociedade, focalizam primordialmente a busca por construir um conhecimento teórico que integre a noção experiencial do consumo com o sistema cultural e simbólico dos sujeitos, construído e envolvido no fluxo da vida social 
cotidiana. Não é demais destacar que essa abordagem parece ser original na academia brasileira de marketing e se constitui, portanto, na principal implicação deste ensaio para a literatura.

Não menos importante é a constatação de que, em um país com uma diversidade social e cultural tão grande como o Brasil, torna-se bastante ampla a gama de possibilidades para pesquisas que retratem a realidade vivida dos consumidores, em práticas que se estendem de situações corriqueiras até não tradicionais de consumo. Ganham espaço, também, os estudos regionais nos quais seria possível investigar hábitos, rituais e mitos de consumo de infinidade de produtos e serviços, bem como construções simbólicas de posses e experiências pelos indivíduos envolvidos.

\section{E quanto aos métodos de pesquisa?}

Frente a toda essa discussão teórica e possíveis interlocuções entre as experiências de consumo e a teoria da cultura do consumo, é importante ponderar sobre as possibilidades metodológicas que envolveriam tais estudos. Conforme já reforçado anteriormente, os campos da experiência do consumo e da cultura do consumo são marcados pela presença de múltiplas conversações, o que favorece, além da riqueza teórica, a incorporação de diversos métodos e técnicas de investigação oriundas de outras áreas do conhecimento. Esse contexto, fatalmente, conduz a um pluralismo metodológico que pode enriquecer o campo da pesquisa do consumidor.

Uma leitura superficial já indicaria como mais adequada aos estudos do gênero uma perspectiva voltada ao interpretacionismo na qual os procedimentos metodológicos poderiam privilegiar um caráter qualitativo, aberto e exploratório, enfatizando a experiência subjetiva, os significados, os processos envolvidos e o contexto particular de uma realidade e que gere insumos para o entendimento da realidade. Além disso, que trate de forma aprofundada os dados, de maneira a permitir que se debata melhor as questões relacionadas às interações sociais em um tempo determinado e em estruturas sociais particulares. Arnould e Thompson (2005) defendem que dados qualitativos, bem como coleta e técnicas de análise de dados qualitativos têm sido usuais em estudos envolvendo cultura do consumo, uma vez que as dimensões experienciais e socioculturais do consumo não são plenamente acessíveis por meio de experimentos, surveys ou modelagens mais quantitativas.

Já no que tange às abordagens metodológicas para o estudo das experiências de consumo, percebem-se estudos baseados em epistemologias positivistas e orientadas tanto à mensuração quanto à quantificação das experiências. Entre eles, podem ser identificados os estudos de Havlena e Holbrook (1986), Laverie, Kleine III e Kleine (1993), Richins (1997), Mathwick, Malhotra e Rigdon (2001), Brakus (2001), Pullman e Gross (2003). Porém, destacam-se nesse campo estudos que se apoiam em abordagens de cunho mais humanista e, portanto, fenomenológicas e interpretativistas das experiências de consumo. Thompson, Locander e Pollio (1989) apresentam o método fenomenológico-existencial como uma importante alternativa para o estudo das experiências do consumidor. Shankar, Elliot e Goulding (2001) defendem a utilização da análise de narrativas como uma potencial contribuição para o entendimento de como os consumidores estruturam e interpretam suas experiências de consumo. Outro estudo, conduzido por Arnould e Price (1993), tentou conciliar diversas abordagens de pesquisa como focus group, entrevistas em profundidade, observação participante e até surveys para entender as experiências de consumo extraordinárias nos encontros de serviços. Pode ser citado também o trabalho de Holbrook (2006b), que, numa abordagem interpretativista, propõe o uso de fotografias para evocar experiências dos indivíduos. Na mesma linha, Goulding (2000), mediante uma abordagem interpretativa, e 
utilizando a metodologia da grounded theory, pesquisou as experiências de consumo de visitantes de museus nos Estados Unidos.

Sendo assim, um dos métodos originados na Antropologia - a etnografia - poderia ser de grande valia para os pesquisadores que buscam estabelecer uma interlocução entre experiência de consumo e a teoria da cultura do consumo. Em termos práticos, segundo a visão de Atkinson e Hammersley (1994), a etnografia se refere a uma forma de pesquisa social com as seguintes características: (1) uma forte ênfase na exploração da natureza de um fenômeno social particular, mais do que estabelecer ou testar hipóteses; (2) uma tendência de trabalhar com dados desestruturados, isto é, dados que não foram codificados em termos de uma série de categorias analíticas; (3) investigação detalhada de um pequeno número de casos; (4) análise de dados envolvendo interpretação explícita de significados e funções das ações humanas.

Dessa forma, para Godoy (1995), a pesquisa etnográfica abrange a descrição dos eventos que ocorrem na vida de um grupo e a interpretação do significado desses eventos para a cultura do grupo. Para essa autora, o trabalho de campo é o coração da pesquisa etnográfica, pois sem um contato intenso e prolongado com a cultura ou com o grupo em estudo será impossível ao pesquisador descobrir como seu sistema de significados culturais está organizado, como se desenvolveu e como influencia o comportamento grupal. Assim, de acordo com Rocha e Rocha (2007), por meio do estudo etnográfico é possível 'acessar' as formas pelas quais os grupos sociais atribuem significado aos produtos e serviços, ou seja, como experimentam o consumo e, dessa forma, traduzem afeto, desejo e relações sociais, construindo uma visão de mundo.

Conforme a proposta apresentada por Pinto e Santos (2008), atrelada à etnografia, poderia ser defendida a utilização da grounded theory. Esta foi concebida como uma metodologia que, baseada em dados sistematicamente coletados e analisados, leva ao desenvolvimento de uma teoria (STRAUSS; CORBIN, 1998) ou ao fornecimento de uma nova abordagem para um conhecimento já existente (GOULDING, 2002). Esta teoria desenvolve-se durante o processo de pesquisa e é um produto de contínuas interações entre análise e coleta sistemáticas de dados pertencentes a um fenômeno (STRAUSS; CORBIN, 1998). Essa metodologia seria interessante nesse contexto, visto que ela permitiria, juntamente com a etnografia, a composição de um 'estilo' de pesquisa mais atento ao mundo vivido dos consumidores. Essa é uma preocupação que tem incomodado diversos pesquisadores no campo dos estudos de consumo preocupados em explorar os significados construídos e as experiências vividas pelas pessoas, e que os tem incentivado a buscar soluções alternativas capazes de lançar mão de teorias-metodologias complementares que permitam lidar com as ambiguidades, a fluidez e as contradições da 'vida real'.

Outra possibilidade de investigações, na temática discutida no presente artigo, seria a utilização do método fenomenológico de pesquisa. Os estudos de base fenomenológica conseguem explicar por que e como as relações sociais ocorrem em seu ambiente natural. Pode-se afirmar, portanto, que a fenomenologia admite que o comportamento é explicado pelo significado dado às ações, oriundo de interpretações das pessoas sobre o fenômeno (MOREIRA, 2004; CERCHIARO; SAUERBRONN; AYROSA, 2004).

Também seria possível a incorporação de outras técnicas qualitativas, ainda incipientes na pesquisa do consumidor, principalmente no Brasil, como as técnicas projetivas, os estudos observacionais, a técnica denominada ZMET (Zaltman Metaphor Elicitation Technique), as pesquisas visuais como autodriving, entre diversas outras que, combinadas ou não, podem contribuir para o entendimento das experiências de consumo na perspectiva da cultura do consumo. Complementarmente, seria útil a incorporação de métodos do campo da 
investigação social como utilização de vídeos, filmes, fotografias, bem como análise semiótica, análise de discurso, análise retórica, entre outras (BAUER; GASKEL, 2002).

Não seria inapropriado enfatizar que a conjugação de algumas dessas técnicas seria de estimado valor para um maior entendimento dos fenômenos envolvidos e, principalmente, para 'consolidar' o campo de cultura e consumo como interdisciplinar, plural e 'aberto' a contribuições de várias áreas do conhecimento.

Por fim, vale destacar que essas são apenas algumas sugestões de metodologias de pesquisa. Fica implícito que o campo de pesquisa nessa temática está aberto a novas epistemologias que, de forma complementar, podem proporcionar aos pesquisadores um arsenal de práticas e procedimentos para compreender os fenômenos envolvidos.

\section{Reflexões Finais}

Por meio das discussões contempladas anteriormente, pode-se chegar a algumas reflexões finais que parecem ser pertinentes. Em primeiro lugar, é importante ressaltar que as pesquisas do consumidor têm se apoiado em técnicas mais quantitativas de coleta e análise de dados. A proposta defendida por este artigo caminha no sentido de que é preciso trazer para o campo outras metodologias de base interpretativa e, portanto, mais abertas à voz do consumidor na sua vida cotidiana. Ademais, fica fácil perceber que a opção por estas metodologias adere a uma perspectiva preocupada com o entendimento do marketing como fenômeno social constituído por ações cotidianas. Dessa forma, vale destacar que os argumentos defendidos ao longo do trabalho buscam estabelecer uma 'lógica' de pesquisa que permita construir entendimentos preocupados em efetivamente dialogar com a "realidade" dos sujeitos pesquisados; em tratar os consumidores na relação uns com os outros e com o mundo próprio deles.

No mesmo sentido, esta proposta vai ao encontro dos objetivos dos estudos que buscam focar esforços no entendimento do cotidiano do consumidor com todas suas nuances e tentam captar um pouco da lógica simbólica e dos significados articulados socialmente presentes nos diversos atos de consumo, incluindo toda a complexidade da noção experiencial do consumo. Ou seja, buscou-se incorporar aos aspectos experienciais do consumo uma dimensão social, ressaltando o seu significado simbólico-cultural - significado que não se limita ao consumidor individual, isolado, obediente e sempre fiel à simples ordem econômica, material e funcional do consumo, mas que está sempre em trânsito, sendo criado e transferido, desfilando fugaz no mundo culturalmente constituído, nos produtos e serviços e nos próprios consumidores. Dessa forma, parece lícito afirmar que começa a se definir um 'novo campo' de estudos, não somente focado no comportamento do consumidor, mas em toda a complexidade que envolve os atos experienciais do consumo nos circuitos das trocas sociais e que são eminentemente simbólicos.

Em segundo lugar, é interessante ressaltar o desafio que é construir uma 'conversação' adequada de temáticas ainda pouco desenvolvidas teoricamente, oriundas de campos de conhecimentos diversos, com autores com formações teóricas distintas e, principalmente, com pouca utilização no campo do marketing no Brasil. Dessa forma, as reflexões aqui expostas são de caráter preliminar, pois até mesmo nos estudos de consumo, a cultura do consumo ainda é considerada pouco usual nos trabalhos dos pesquisadores desse campo. A mesma questão pode ser levantada no tocante à experiência de consumo, visto que a literatura da temática é lacunar em diversos pontos e carente de pesquisas empíricas mais aprofundadas. Assim, é de extrema importância uma leitura cuidadosa dos autores mencionados, pois muitos deles basearam frequentemente suas reflexões em 
outros contextos e culturas, épocas diferentes da sociedade de consumo e muitas vezes não focadas em situações peculiares de consumo.

Em terceiro lugar, parece ser altamente relevante afirmar que a proposta apresentada neste artigo vai ao encontro daqueles pesquisadores da área de marketing preocupados e direcionados em explorar os significados construídos e as experiências vividas pelas pessoas. Pessoas 'comuns' que, no seu cotidiano diário, trabalham, se relacionam, sonham, consomem, enfim, vivem em diferentes contextos, seja em grandes centros urbanos ou em pequenas cidades, seja em luxuosas casas de bairros sofisticados ou em apertados cômodos de favelas ou vilas, seja comprando em grandes shopping centers ou na mercearia da esquina. Ou, ainda, a integração da noção experiencial do consumo e da teoria da cultura do consumo pode ser encarada como uma tentativa de entender os diversos relacionamentos que surgem entre os consumidores, entre empresa e consumidor, e entre as marcas e os consumidores diretamente num contexto social, tratando o conhecimento como um empreendimento de construção conjunta. Complementarmente, a proposição das interlocuções discutidas anteriormente poderia servir como uma alternativa para aqueles estudiosos interessados em encontrar teoriasmetodologias complementares que permitam lidar com ambiguidades, fluidez e contradições da 'vida real' vivenciadas pelos consumidores. As metodologias propostas para a investigação dessa temática podem se constituir numa possibilidade de se chegar àquilo que os consumidores realmente fazem, por meio de estudos que privilegiem uma visão 'de perto e de dentro', com o pesquisador procurando entender a lógica que orienta a vida desses consumidores em seu próprio contexto natural.

É útil enfatizar, também, que não somente é possível, mas essencial, avançar por novos enquadramentos conceituais sobre o consumo e o consumidor que ultrapassem a forma costumeira de encará-los somente por meio de uma dimensão residual, individual ou utilitária advinda de uma visão reduzida. Uma das grandes reflexões do trabalho é a de que se deve compreender o consumo como uma espécie de facilitador, propiciador, 'construtor' e 'articulador' de relações sociais. Assim, a ideia de compreender as experiências de consumo no plano cultural e simbólico implica atrelar os significados dessas experiências às dinâmicas de sociabilidade às quais se entrelaçam.

Dessa forma, vale retornar às inquietações que motivaram a elaboração deste artigo para se concluir que não é somente possível, mas altamente desejável estabelecer ricas e profícuas discussões acerca das possibilidades de interlocuções entre a literatura relacionada às experiências de consumo e à cultura do consumo, propondo intrigantes questões de pesquisa, além de novas epistemologias e metodologias que, embora ainda pouco usuais no campo da pesquisa do consumidor no Brasil, possam contribuir para uma perspectiva interessada em entender o consumo sob uma perspectiva experiencial como fenômeno cultural e carregado de aspectos simbólicos. Fica clara, portanto, a importância desta discussão para a pesquisa do consumidor em nosso país.

Não se poderia deixar de mencionar que os resultados gerados por estudos que busquem entender o consumo por meio da conjugação da perspectiva experiencial com a perspectiva da teoria da cultura do consumo podem contribuir para o ensino em Administração, mais precisamente no campo da pesquisa do consumidor. Trabalhos nessa linha podem trazer à baila, entre outros pontos, a questão da confiabilidade das teorias gerais sobre o consumidor, normalmente embasadas na literatura predominantemente estrangeira. Essa confiabilidade pode ser questionada quanto à sua capacidade explicativa em contextos específicos, como no caso de experiências de consumo por diversos grupos de consumidores brasileiros, tais como os de baixa renda, da terceira idade, de adolescentes, de portadores de deficiência, bem como aqueles residentes nas diversas regiões do país e nas cidades do interior. Assim, os estudantes poderiam ter acesso a uma descrição rica da realidade 
nacional, bem como a teorias e entendimentos mais contextualizados gerados por peculiaridades históricas, culturais e sociais do consumidor brasileiro.

Cabe destacar que este trabalho buscou trazer para a discussão algumas reflexões, possibilidades de interlocução acerca da cultura do consumo e da abordagem experiencial do consumo, ao mesmo tempo em que lançou luz sobre as possibilidades de pesquisas que poderiam 'arejar' esse campo do marketing com novas problemáticas e diferentes formas de enxergar o consumo. A intenção é propor a 'inauguração' de novas linhas de pesquisas focadas não mais no comportamento do consumidor somente, mas sim afeitas a temas relativos ao consumo entendido, entre outras coisas, como uma estratégia utilizada no cotidiano pelos mais diferentes grupos sociais para auxiliar na tentativa de definir diferentes situações em termos de direitos, estilo de vida e identidades, bem como a determiná-lo como uma categoria central da sociedade contemporânea (BARBOSA; CAMPBELL, 2006).

Porém, o desafio não termina aqui. Discussões mais amplas, envolvendo os pesquisadores não somente da área de marketing, mas de campos fronteiriços como a antropologia, a sociologia, a psicologia, entre diversos outros, são essenciais e extremamente úteis. Este artigo, portanto, parece, humildemente, cumprir seu objetivo de servir principalmente como um convite à discussão para aqueles pesquisadores que, ávidos por desvendar os complexos fenômenos envolvendo o consumo, estão abertos a novas propostas e 'novos olhares', bem como convencidos e dispostos a utilizar novos métodos de investigação em diversas temáticas que fazem parte do dia a dia das inúmeras situações relacionadas ao consumo das pessoas, famílias, grupos e comunidades em toda a sua amplitude e complexidade.

\section{Referências}

ADDIS, Michela; HOLBROOK, Morris B. On the Conceptual Link Between Mass Customization and Experential Consumption: An explosition of subjectivity. Journal of Consumer Research, v. 1, n. 1, p. 50-66, 2001.

ARNOULD, Eric J.; PRICE, Linda L. River Magic: Extraordinary experience and the extended service encounter. Journal of Consumer Research, v. 20, June 1993.

ARNOULD, Eric J.; THOMPSON, Craig J. Consumer Culture Theory (CCT): Twenty Years of Research. Journal of Consumer Research, v. 31, Mar. 2005.

ATKINSON, Paul; HAMMERSLEY, Martyn. Etnography and Participant Observation. In: DENZIN, Norman K.; LINCOLN, Yvonna S. Handbook of Qualitative Research. $2^{\mathrm{a}}$ ed. Thousand Oaks, CA: Sage, 1994.

AZEVEDO BARBOSA, Maria de L. de. Bem-vindo a uma Experiência Extraordinária: Proposições para uma interpretação sobre consumo de serviços. In: ENCONTRO DE MARKETING, 2., 2006, Rio de Janeiro. Anais... Rio de Janeiro: ANPAD, 2006.

BARBOSA, Lívia. Apresentação. In: BARBOSA, Lívia; CAMPBELL, Colin (Org.). Cultura, Consumo e Identidade. Rio de Janeiro: Editora FGV, 2006.

BARBOSA, Lívia; CAMPBELL, Colin. O Estudo do Consumo nas Ciências Sociais Contemporâneas. In: BARBOSA, Lívia; CAMPBELL, Colin (Org). Cultura, Consumo e Identidade. Rio de Janeiro: Editora FGV, 2006.

BARROS, Carla. Consumo, Hierarquia e Mediação: Um estudo antropológico no universo das empregadas domésticas. In: EnANPAD, 30. Anais... Salvador: ANPAD, 2006.

BAUDRILLARD, Jean. A Sociedade de Consumo. Lisboa: Edições 70, 2005.

BAUER, Martin W.; GASKELL, George. Pesquisa Qualitativa com Texto, Imagem e Som: um manual prático. PetrópolisRJ: Vozes, 2002.

BELK, R. Possessions and the extended self. Journal of Consumer Research, v. 15, Set. 1988.

BITNER, Mary J. Servicescape: the impact of physical surroundings on customers and employees. Journal of Marketing 56, n. 2, abr. 1992. 
BRAKUS, Josko. A Theory of Consumer Experiences. Columbia University, 2001. (Tese de Doutorado).

BRASIL, Vinícius S. Experiência de Consumo: aspectos conceituais, abordagens metodológicas e agenda de pesquisa. In: EnANPAD, 31. Anais... Rio de Janeiro: ANPAD, 2007.

CAMPBELL, Colin. A Ética Romântica e o Espírito do Consumismo Moderno. Rio de Janeiro: Rocco, 2001.

CARÙ, Antonella; COVA, Bernard. Revisiting Consumption Experience: a more humble but complete view of the concept. Marketing Theory, v. 3, n. 2, p. 267-286, 2003.

CASOTTI, Letícia M. Como Enxergar Diferenças no Consumidor? Algumas reflexões sobre os caminhos do marketing. In: EMA, 1, 2004, Porto Alegre. Anais... Porto Alegre: ANPAD, 2004.

CERCHIARO, I. B.; SAUERBRONN, J. F. R.; AYROSA, E. A. T. Uma Visão Alternativa da Pesquisa em Marketing: como a Fenomenologia pode contribuir para gerar conhecimento em marketing. In: EMA, 1, 2004, Porto Alegre. Anais... Porto Alegre: ANPAD, 2004.

DOUGLAS, Mary; ISHERWOOD, Baron. O Mundo dos Bens: Para uma antropologia do consumo. Rio de Janeiro: Editora UFRJ, 2006.

FALK, Pasi; CAMPBELL, Colin. The Shopping Experience. London: Sage Publications, 1997.

FARIA, Salomão A. Em Busca da Inovação no Marketing Brasileiro: Discutindo o Processo de Publicação de Artigos em Revistas e Congressos. In: EMA, 1, 2004, Porto Alegre. Anais... Porto Alegre: ANPAD, 2004.

FEATHERSTONE, Mike. Cultura de Consumo e Pós-modernidade. São Paulo: Nobel, 1995.

GODOY, A. Pesquisa Qualitativa - tipos fundamentais. Revista de Administração de Empresas, v. 35, n.3, p. $20-29,1995$.

GOULDING, Christina. The Museum Environment and the Visitor Experience. European Journal of Marketing, v. 34, n. 3/4, p. 261-278, 2000.

Grounded Theory: a practical guide for management, business and market researchers. London: Sage Publications, 2002.

HAVLENA, William J.; HOLBROOK, Morris B. The Varieties of Consumption Experience: Comparing two typologies of emotion in consumer behavior. Journal of Consumer Research, v. 13, Dec. 1986.

HOLBROOK, Morris B. The consumption Experience - Somethig new, something old, Something borrowed, something sold: part 1. Journal of Macromarketing, 26; 259, 2006a.

HOLBROOK, Morris B.; HIRSCHMAN, Elizabeth C. The Experiential Aspects of Consumption: Consumer fantasies, feelings, and fun. Journal of Consumer Research, v. 9, p. 132-140, Sept. 1982.

Consumption Experience, Customer Value, and Subjective Personal Introspection: An illustrative photographic essay. Journal of Business Research, 59, p. 714-725, 2006b.

LAVERIE, Debra A.; KLIENE III, Robert E.; KLEINE, Susan S. Linking Emotions and Values in Consumption Experiences: An exploratory study. Advances in Consumer Research, v. 20. 1993.

LOFMAN, Brian. Elements of Experiential Consumption: An exploratory study. Advances in Consumer Research, v. 18. 1991.

LOURENÇO, Cléria D. S.; FERREIRA, Patrícia A.; ROSA, Alexandre R.; SILVA, Sabrina S. Etnografia e Grounded Theory na Pesquisa de Marketing de Relacionamento no Mercado Consumidor: Uma Proposta Metodológica. In: EnEPQ, 1. Anais ... Recife: ANPAD, 2007.

MCCRACKEN, Grant. Cultura e Consumo: novas abordagens ao caráter simbólico dos bens e das atividades de consumo. Rio de Janeiro: Mauad, 2003.

MATHWICK, Charla; MALHOTRA, Naresh; RIGDON, Edward. Experiential Value: conceptualization, measurement and application in the catalog and internet shopping environment. Journal of Retailing, n. 77, p. 39-56, 2001.

. Cultura e Consumo: Uma explicação teórica da estrutura e do movimento do significado cultural dos bens de consumo. Revista de Administração de Empresas, v. 47, n.1, p. 99-115, jan./mar. 2007.

MELLO, S. C. B. O que é Conhecimento em Marketing no Brasil, Afinal? Revista de Administração Contemporânea, v. 10, n. 2, abr./jun. 2006

MILLER, Daniel. Teoria das Compras: o que orienta as escolhas dos consumidores. São Paulo: Nobel, 2002.

MOREIRA, Daniel A. O Método Fenomenológico na Pesquisa. São Paulo: Pioneira Thomson Learning, 2004.

PINE II, B. Joseph; GILMORE, James H. Welcome to the Experience Economy. Harvard Business Review, July-Aug. 1998. 
PINTO, Marcelo de R.; SANTOS, Leonardo L. S. Em Busca de uma Trilha Interpretativista para a Pesquisa do Consumidor: Uma Proposta Baseada na Fenomenologia, na Etnografia e na Grounded Theory, RAE-Eletrônica, v. 7, n. 2, jul./dez. 2008.

PULLMAN, Madeleine; GROSS, Michael. Welcome to your Experience: where you can chack out anytime you'd like, but you can never leave. Journal of Business and Management, v. 9, n. 3, p. 215-232, 2003.

RICHINS, Marsha L. Measuring Emotions in the Consumption Experiences. Journal of Consumer Research, v. 24, p. 127-146, Sept. 1997.

ROCHA, Everardo. Magia e Capitalismo: um estudo antropológico da publicidade. São Paulo: Brasiliense, 1995.

. Representações do Consumo: Estudos sobre a narrativa publicitária. Rio de Janeiro: Editora PUC-Rio, 2006.

ROCHA, Angela da; ROCHA, Everardo. Paradigma Interpretativo nos Estudos de Consumo: Retrospectiva, Reflexões e uma Agenda de Pesquisas para o Brasil. Revista de Administração de Empresas, v. 47, n. 1, p. 71-80, jan./mar. 2007.

ROSSI, Carlos Alberto V.; HOR-MEYLL, Luiz Fernando. Explorando Novas Trilhas na Pesquisa do Consumidor. In: EnANPAD, 25․ Anais... Campinas: ANPAD, 2001

SAHLINS, Marshall D. Cultura e Razão Prática. Rio de Janeiro: Jorge Zahar, 2003.

SCHMITT, Bernd H. Marketing Experimental: Sua empresa e suas marcas conquistando o sentir e o pensar o agir e o identificar-se dos clientes. São Paulo: Nobel, 2000.

SHANKAR, Avi; ELLIOT, Richard; GOULDING, Christina. Understanding Consumption: Contributions from a Narrative Perspective. Journal of Marketing Management, v. 17, p. 429-453. 2001.

SLATER, Don. Cultura do Consumo e Modernidade. São Paulo: Nobel, 2002.

STRAUSS, Anselm; CORBIN, Juliet. Basics of Qualitative Research: Grounded theory procedures and techniques. Newbury Park, CA: Sage Publications, 1998.

THOMPSON, Craig; HIRSCHMAN, Elizabeth C. Understanding the Socialized Body: A poststructuralist analysis of consumers. Journal of Consumer Research, v. 22, p. 139-153, Sept. 1995.

THOMPSON, Craig J.; LOCANDER, William B.; POLLIO, Howard R. Putting Consumer Experiences Back into Consumer Research: The philosophy and method of existential-phenomenology. Journal of Consumer Research, v. 16, p. 133-146, Sept. 1989.

VEBLEN, Thorstein. A Teoria da Classe Ociosa: um estudo econômico das instituições. São Paulo: Nova Cultura, 1988. 